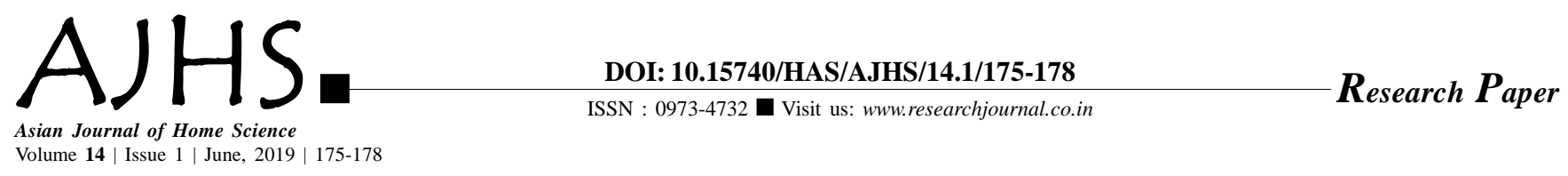

\title{
Effect of age on women's knowledge, attitude and practice (KAP) behaviour as a consumer towards food adulteration its safety measures
}

Author for correspondence :

Anita Gautam

Kevalpatti Ramasarey

Mahavidyalaya (LU), Rajendra

Nagar, Banthra, Sikanderpur,

Lucknow (U.P.) India

Received: 27.09.2018; Revised: 07.05.2019; Accepted: 16.05.2019

ABSTRACT : Food is the basic necessity of life. One works hard and earns to satisfy our hunger and relax (enjoy) later. But at the end of the day, many of us are not sure of what we eat. Food adulteration is undoubtedly a social evil which can be regarded as the outcome of an interaction between a number of social, economic, technical and human behavioural factors. It is a manifestation of a sick society and can be regarded as a crime similar to other crimes like theft, burglary or murder. It is felt that there is an urgent need for an impartial scientific study to determine the prevalence of food adulteration at household level in the country. It is equally important for the consumer to know the common adulterants and their effect on health.On the basis of pilot study 300 samples were selected from three different areas of Lucknow district through multistage random sampling technique. For the study married women of age groups (i.e. 15 to 49) were considered as study subjects who carried their families. Further, to carry out the study pre-designed and pre tested questionnaire was used. It is found in the study that, there is no significant association between age and KAP scores was observed for all the items except cereals and spices regarding adulteration in food stuffs. Except for the frequency of adulteration in mango-carbide, banana-carbide, milk-water, chilli-brick powder, chilli-dirt for all the other items, the difference among different age groups was not significant statistically $(\mathrm{P}>0.05)$. Except for harmful effects of cereals, for none of the other items a significant difference among different age groups was observed $(\mathrm{P}>0.05)$. For cereals, mean scores of those aged 1524 yrs were significantly higher as compared to all the other age groups $(\mathrm{P}<0.001)$. The KAP scores of consumer's shows that, statistically there is no significant association between consumer age and mean scores was observed for the variables consumer rights, consumer protection, consumer laws and food safety. However, for the item food marks an inverse relation between KAP scores and age was observed which was also significant statistically $(\mathrm{P}=0.002)$.

KEY WORDS: Adulteration, KAP

- HOW TO CITE THIS PAPER : Gautam, Anita (2019). Effect of age on women's knowledge, attitude and practice (KAP) behaviour as a consumer towards food adulteration its safety measures. Asian J. Home Sci., 14 (1) : 175-178, DOI: 10.15740/HAS/AJHS/14.1/175-178. Copyright@ 2019: Hind Agri-Horticultural Society. 